\title{
The short-term effects of intravitreal aflibercept injections and dexamethasone implant on ocular hemodynamics in retinal vein occlusions
}

This article was published in the following Dove Press journal:

Therapeutics and Clinical Risk Management

\author{
Emine Ciloglu (D) \\ Ayse Yıldırım Celikdemir ${ }^{2}$ \\ 'Department of Ophthalmology, Adana \\ City Training and Research Hospital, \\ Adana, Turkey; ${ }^{2}$ Department of \\ Radiology, Adana City Training and \\ Research Hospital, Adana, Turkey
}

Purpose: To determine the early effects of intravitreal anti-VEGF and dexamethasone application on blood flow velocities in patients with retinal vein occlusions.

Methods: The ophthalmic (OA) and the central retinal arteries (CRAs) of the affected and unaffected eyes of 21 patients with central retinal vein occlusion (CRVO), and 26 patients with branch retinal vein occlusion (BRVO) were investigated by Color Doppler imaging (CDI). Peak systolic volume (PSV), end diastolic volume (EDV), and average blood velocity (Vmean) of the CRA and OA were measured and resistive indexes (RI) were calculated at pre-injection and the 1st week and 1st month post-injection.

Results: There was no statistically significant difference between the OA values for affected and unaffected eyes in the CRVO group before treatment. The CRA, EDV, and Vmean values were significantly lower in affected eyes. Blood flow velocities of both CRA and OA were not significantly different than in the fellow unaffected eyes in the BRVO group. The differences between PSV, EDV, and Vmean measurements of OA and CRA at different times pre- and post-injection in response to anti-VEGF and dexamethasone treatment in the CRVO group were significant; but there was no difference in RI value. OA blood flow velocity measurements were not statistically different post-injection in the BRVO group; however, the values of PSV and EDV of CRA decreased post-injection.

Conclusion: Intravitreal anti-VEGF and dexamethasone implant may induce retinal arteriolar vasoconstriction in patients with retinal vein occlusion.

Keywords: retinal vein occlusion, anti-VEGF, dexamethasone, ocular doppler ultrasonography

\section{Introduction}

Retinal vein occlusion (RVO) is one of the most common type of retinal vascular disorders and causes sudden painless unilateral loss of vision. The physiopathology is complex and unclear. Arteriosclerosis, hyperviscosity, coagulation disorders are some of the published reasons. ${ }^{1}$ RVO can be divided into two main types: branch retinal vein occlusion (BRVO) and central retinal vein occlusion (CRVO). Generally, BRVO has a better prognosis than CRVO. Cystoid macular edema (CME) is the main cause of impaired vision in RVO. $^{2}$ The damage of tightjunctions of capiller endothelial cells and vitreoretinal adhesion leads to breakdown of blood retinal barrier. Secretion of vasopermeability factors into the vitreous from retina causes fluid flux from vessels to tissue. ${ }^{3}$ The treatment of RVO has three main states: identification and treatment of modifiable risk factors, specific treatment of vascular occlusion and treatment of complications such as macular edema.
Correspondence: Emine Ciloglu

Adana Șehir Eğitim ve Araștırma

Hastanesi, Göz Hastalıkları Kliniği, 0 I I60

Adana, Türkiye

Tel +90505842 108।

Email drciloglu@gmail.com 
Resolution of the macular edema, before the foveal photoreceptor layer damaged, is important for the success of treatment. Vascular endothelial growth factor (VEGF) is expressed at increased concentrations in the setting of macular edema. It is known that VEGF is a potent promoter of vascular permeability. ${ }^{4}$ The management of CME secondary to RVO has improved in recent times with the therapy based on injection of anti-VEGF molecules and steroids. ${ }^{5}$ They are administered by intravitreal injection; from vitreous they diffuse to retinal vessels where they counteract the detrimental effects of VEGF on microvascular proliferation and permeability.

Color Doppler imaging (CDI) is a commonly used noninvasive technique for assessing blood flow parameters in different parts of the body. CDI is a reproducable technique that is shown to be useful in evaluating ocular hemodynamic changes in several orbital and retinal vascular diseases. ${ }^{6}$

This study was designed to examine the blood velocities of ophthalmic and central retinal arteries (CRAs) of the affected and non-affected fellow eyes in patients with RVO to determine the short-term effect of intravitreal injection treatment on these values.

\section{Materials and methods}

Forty-seven (47) eyes of consecutive patients with macular edema secondary to unilateral untreated acute RVO are included in the study. Their fellow eyes comprised the control group. The diagnosis of RVO and macular edema was confirmed by fluorescein angiography (FFA) and spectral domain optical coherence tomography (SD-OCT).

The study protocol was approved by the Adana City Training and Research Hospital Ethics Committee. The study adhered to the tenets of the Declaration of Helsinki and written informed consent was taken from the patients.

The inclusion criteria were the presence of macular edema that involved the fovea secondary to non-ischemic RVO. History of glaucoma, aphakia or presence of anterior chamber lens, any retinal vascular disease other than RVO (ie, diabetic retinopaty, age-related macular degeneration, macular edema for other reasons), previous ocular surgery, any ocular infection were exclusion criteria.

All patients underwent a complete ophthalmological examination including best corrected visual acuity, slitlamb examination, Goldmann applanation tonometry and indirect ophthalmoscopy after pharmacological mydriasis. FFA and SD-OCT (Retina Scan RS 3000 Advance, Nidek Inc, CA, USA) were performed with all patients during the initial examination.
All patients included to the study received an intravitreal injection of aflibercept (Eylea ${ }^{\circledR}$; Bayer Leverkusen, Leverkusen, Germany) ( $2 \mathrm{mg} / 0.05 \mathrm{~mL}$ ) or a sustained-release dexamethasone implant (Ozurdex; Allergan, Irvine, CA, USA) under sterile conditions. Prior to injection, the topical anesthetic Alcaine $0.5 \%$ (proparacaine $\mathrm{HCl}$ ) was administered. The area around the eye was sterilized with $10 \%$ povidone-iodine and $5 \%$ povidone iodine was administered in the conjunctival sac. Intravitreal aflibercept $2 \mathrm{mg}$ was injected with a 30 -gauge needle through the inferotemporal pars plana at $3.5 \mathrm{~mm}$ posterior to the limbus. The needle was inserted approximately 1.0 $\mathrm{cm}$ into the globe, and the injection was performed. Intravitreal Dexamethasone implant (Ozurdex) was injected into the vitreous through the pars plana using the standard, single use, preloaded 22-gauge applicator. After injection, a sterile cotton swab was placed on the injection site to prevent reflux of the medicine or vitreous. Each eye was examined for perfusion of the CRA. All intravitreal injections were performed by the same surgeon. Re-treatments were done in monthly intervals. CDI for retrobulbar blood flow assessments were performed at all visits.

The blood flow velocities of the CRA and ophthalmic artery (OA) obtained from affected and unaffected control eyes of patients with CRVO and BRVO at initial, 1st week and 1 st month after injection are shown in Figure 1 (Figure 1).

CDI was used to measure the blood velocity of the CRA and OA. CDI was performed with the use of 7.5 $\mathrm{MHz}$ linear array probe (Toshiba Sonolayer SSH-140). All measurements were done by the same blinded physician (AC) without informed about the clinical diagnoses at the Radiodiagnostic Department of our hospital. CDI was performed from superior layer of the eye by using methylcellulose gel on the eyelid of patient lying at supine position. The physician put her hand on the orbital margin to minimize the pressure on the globe. After three spectral waveforms were obtained, the image was frozen and peak systolic velocity (PSV), end diastolic velocity (EDV), mean velocity (Vmean) values were noted for CRA and OA. Resistive index (RI) for each arteria is calculated and noticed (PSV-EDV/PSV).

\section{Statistical analysis}

Statistical analyses were performed by SPSS 20.0 (IBM Inc., Chicago, IL, USA). Descriptive statistics were presented as mean \pm SEM in tables. Most of the measurements were not distributed normally tested by KolmogorovSmirnov test of normality. Mann-Whitney $U$ test was used for comparing two independent groups with respect 


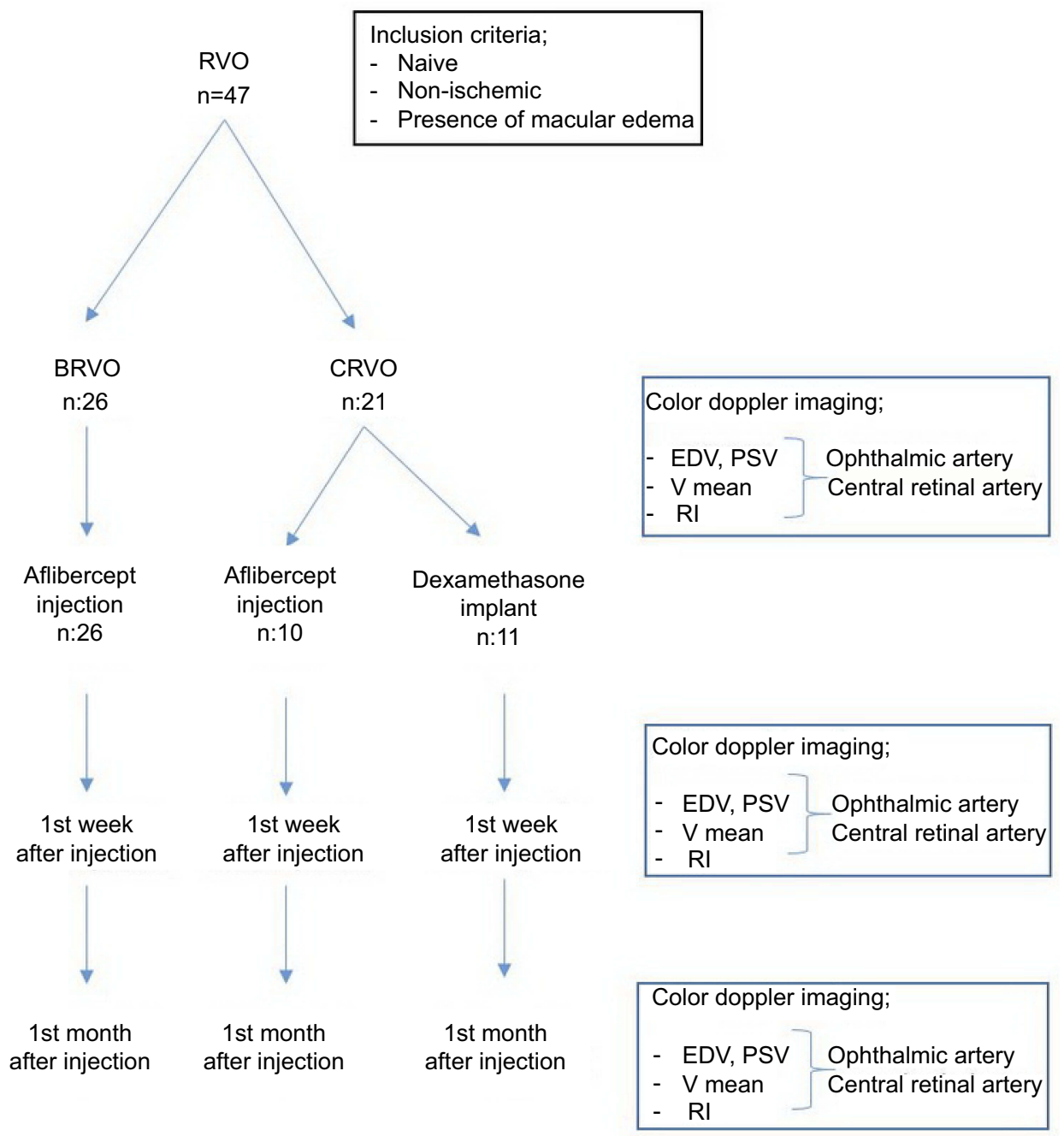

Figure I Flowchart of the study.

Abbreviations: RVO, Retinal vein occlusion; BRVO, Branch retinal vein occlusion, CRVO, Central retinal vein occlusion; EDV, End diastolic volume; PSV, Peak systolic volume; Vmean, Average blood velocity; RI, Resistive index.

to injection type. Friedman's two-way analysis of variance was used for comparing pre-injection, post-injection 1st week and 1st month measurements of OA. For the difference between the injected eyes and other fellow eyes as a control group, Wilcoxon signed rank test was used. Binary logistic regression models were run to determine the effects of the measurements on CRVO and BRVO injection type groups. In all analyses, $P$-value of less than 0.05 was considered as statistically significant.

\section{Results}

Patients were divided into two groups as CRVO (44.7\% $\mathrm{n}: 21)$ and BRVO (55.3\% n:26). The mean age was 66.55 \pm 2.82 years. The demographic characteristics of patients are in Table 1.
In CRVO and BRVO eyes, the blood flow velocity parameters were obtained and compared with before injection, one week and one month after one dose of anti-VEGF or dexamethasone. And the measurements of BRVO/CRVO eyes before treatment were compared with the healthy fellow eyes.

In the CRVO group, 10 patients had received antiVEGF treatment and 11 patients had received dexamethasone implant. At initial stage before treatment, in CRVO group, in the values for OA, there was no statistically significant difference between the affected and unaffected eyes. For CRA, EDV and Vmean values were significantly lower in affected eyes (Table 2).

In response to anti-VEGF and dexamethasone treatment in CRVO group, the difference between PSV, EDV, Vmean measurements of $\mathrm{OA}$ at different times before and after 
Table I The characteristics of patients

\begin{tabular}{|l|l|l|l|}
\hline & $\begin{array}{l}\text { CRVO } \\
\text { (n:2I) }\end{array}$ & $\begin{array}{l}\text { BRVO } \\
\text { (n:26) }\end{array}$ & $\begin{array}{l}\text { All groups } \\
\text { (n:47) }\end{array}$ \\
\hline Age & $72.30 \pm 2.40$ & $55.42 \pm 3.25$ & $66.55 \pm 0.82$ \\
Sex (M/F) & $11 / 10$ & $14 / 12$ & $25 / 22$ \\
Hypertension & 15 & 19 & 34 \\
Duration of macular edema (months) & $2.05 \pm 0.5$ & $2.26 \pm 0.9$ & $2.15 \pm 0.6$ \\
IOP & $16.10 \pm 1.32$ & $15.50 \pm 0.93$ & $15.8 \pm 1.12$ \\
Aflibercept/dexamethasone & $10 / 11$ & $26 /-$ & $36 / 11$ \\
\hline
\end{tabular}

Table 2 Baseline hemodynamic characteristics in central retinal vein occlusion

\begin{tabular}{|l|l|l|l|}
\hline CRVO & $\begin{array}{l}\text { Affected } \\
\text { eye }\end{array}$ & $\begin{array}{l}\text { Unaffected } \\
\text { eye }\end{array}$ & P-value \\
\hline $\begin{array}{l}\text { Ophthalmic artery } \\
\text { PSV }\end{array}$ & $40.73 \pm 0.30$ & $44.5 \pm 4.70$ & 0.247 \\
EDV & $9.00 \pm 1.43$ & $12.5 \pm 1.34$ & 0.475 \\
Vort & $26.0 \pm 2.17$ & $28.5 \pm 2.78$ & 0.266 \\
RI & $2.86 \pm 0.34$ & $2.98 \pm 0.33$ & 0.594 \\
\hline Central Retinal Artery & & & \\
PSV & $18.50 \pm 2.59$ & $22.73 \pm 2.97$ & 0.066 \\
EDV & $6.59 \pm 0.85$ & $8.0 \pm 1.04$ & 0.025 \\
Vort & $12.55 \pm 1.65$ & $15.36 \pm 1.9$ & 0.041 \\
RI & $1.95 \pm 0.25$ & $1.88 \pm 0.29$ & 0.790 \\
\hline
\end{tabular}

injection was significant. But there was no difference in RI value. Similarly, measurements of PSV, EDV, Vmean of the CRA had significant difference between before and after injection (Table 3).

In CRVO group, there was no statistically significant difference between the eyes treated with anti-VEGF or dexamethasone at first week and at first month (Table 4).
In the BRVO group, all patients (26 patients) had received anti-VEGF treatment. In BRVO group before treatment, blood flow velocities of both CRA and OA were not significantly different than the fellow unaffected eyes (Table 5).

In BRVO group, OA blood flow velocity measurements were not statistically significantly different after injection. However, the values of PSV and EDV of CRA decreased after injection (Table 6).

The injections were well tolerated and no serious adverse events were observed. Intraocular pressure (IOP) was increased in most of the patients immediately after the injection, but it was normal after 1 day. Subconjunctival hemorrhage developed after injection in 5 patients who underwent dexamethasone implant. Neither systemic hemodynamic parameters nor IOP changed in response to aflibercept and dexamethasone implant therapy.

\section{Discussion}

In this study, we want to research the blood flow velocities of the CRA and OA of the affected and unaffected fellow eyes in patients with either CRVO and BRVO and to determine the effect of intravitreal injection treatment for macular edema on these values.

Table 3 Changes in hemodynamic parameters in central retinal vein occlusion group after injection

\begin{tabular}{|l|l|l|l|l|}
\hline CRVO & Before injection & Ist week & Ist month \\
\hline Ophthalmic artery & & & & \\
PSV & $40.73 \pm 3.3$ & $31.91 \pm 1.68$ & $31.27 \pm 1.85$ & \\
EDV & $10.05 \pm 1.34$ & $9.36 \pm 1.01$ & $9.45 \pm 0.89$ & 0.037 \\
Vort & $26.0 \pm 2.17$ & $18.77 \pm 2.21$ & $19.45 \pm 1.62$ & 0.069 \\
RI & $2.86 \pm 0.34$ & $2.76 \pm 0.34$ & $2.52 \pm 0.29$ & 0.029 \\
\hline Central Retinal Artery & & & & 0.931 \\
PSV & $18.50 \pm 2.59$ & $14.91 \pm 1.73$ & $11.73 \pm 1.32$ \\
EDV & $6.59 \pm 0.85$ & $6.0 \pm 0.79$ & $4.45 \pm 0.58$ & \\
Vort & $12.55 \pm 1.65$ & $10.64 \pm 1.15$ & $8.09 \pm 0.92$ & 0.002 \\
RI & $1.95 \pm 0.25$ & $1.71 \pm 0.35$ & $1.86 \pm 0.33$ & 0.002 \\
\hline
\end{tabular}


Table 4 The comparison of the hemodynamic parameters in patients who received anti-VEGF or dexamethasone implant

\begin{tabular}{|l|l|l|l|}
\hline CRVO & $\begin{array}{l}\text { Aflibercept } \\
\text { group }\end{array}$ & $\begin{array}{l}\text { Dexamet- } \\
\text { hasone } \\
\text { group }\end{array}$ & P-value \\
\hline $\begin{array}{l}\text { Ophthalmic artery } \\
\text { Ist week PSV }\end{array}$ & $30.4 \pm 2.54$ & $33.17 \pm 2.32$ & 0.429 \\
EDV & $8.4 \pm 1.72$ & $10.17 \pm 1.22$ & 0.429 \\
Vort & $15.3 \pm 4.26$ & $21.67 \pm 1.44$ & 0.126 \\
RI & $3.1 \pm 0.61$ & $2.47 \pm 0.39$ & 0.329 \\
Ist month PSV & $32.2 \pm 2.44$ & $30.5 \pm 2.88$ & 0.537 \\
EDV & $8.6 \pm 0.98$ & $10.17 \pm 1.42$ & 0.429 \\
Vort & $20.4 \pm 1.53$ & $18.67 \pm 2.94$ & 0.429 \\
RI & $2.91 \pm 0.42$ & $2.2 \pm 0.38$ & 0.537 \\
\hline Central Retinal Artery & & & \\
Ist week PSV & $15.2 \pm 2.85$ & $14.67 \pm 2.36$ & 0.429 \\
EDV & $5.40 \pm 1.33$ & $6.5 \pm 0.99$ & 1.000 \\
Vort & $10.7 \pm 1.82$ & $10.58 \pm 1.61$ & 1.000 \\
RI & $2.2 \pm 0.56$ & $1.31 \pm 0.24$ & 0.177 \\
Ist month PSV & $11.0 \pm 1.14$ & $12.33 \pm 2.39$ & 0.792 \\
EDV & $3.8 \pm 0.58$ & $5.0 \pm 0.93$ & 0.429 \\
Vort & $7.4 \pm 0.68$ & $8.67 \pm 1.63$ & 1.000 \\
RI & $2.24 \pm 0.64$ & $1.54 \pm 0.28$ & 0.537 \\
\hline
\end{tabular}

Table 5 Baseline hemodynamic characteristics in branch retinal vein occlusion

\begin{tabular}{|l|l|l|l|}
\hline BRVO & $\begin{array}{l}\text { Affected } \\
\text { eye }\end{array}$ & $\begin{array}{l}\text { Unaffected } \\
\text { eye }\end{array}$ & $P$-value \\
\hline $\begin{array}{l}\text { Ophthalmic artery } \\
\text { PSV }\end{array}$ & $38.5 \pm 3.11$ & $34.44 \pm 3.26$ & 0.132 \\
EDV & $12.56 \pm 1.26$ & $12.63 \pm 1.62$ & 0.955 \\
Vmean & $25.53 \pm 2.11$ & $23.53 \pm 2.42$ & 0.325 \\
RI & $2.30 \pm 0.16$ & $2.08 \pm 0.20$ & 0.211 \\
\hline Central retinal artery & & & \\
PSV & $18.63 \pm 2.94$ & $20.03 \pm 3.01$ & 0.247 \\
EDV & $6.50 \pm 1.13$ & $5.98 \pm 1.32$ & 0.466 \\
Vmean & $12.56 \pm 2.02$ & $14.23 \pm 2.40$ & 0.513 \\
RI & $2.02 \pm 0.19$ & $2.05 \pm 0.19$ & 0.820 \\
\hline
\end{tabular}

We observed a reduction of blood flow velocities in the CRA and OA in patients with CRVO and in the CRA eyes with BRVO after anti-VEGF treatment.

Hemodynamic abnormalities in the retrobulbar arterial circulation of patients with CRVO were reported previously. ${ }^{7-10}$

Pichot et al demonstrated reduction of the retinal artery peak systolic flow and absence of diastolic flow in eyes with CRVO. ${ }^{8}$ Williamson et al found that PSV and EDV in the CRA were lower in the affected eyes than in the fellow and control eyes. ${ }^{10}$ Similarly, we found that in CRVO group, EDV and Vmean values of CRA were significantly lower in affected eyes than in fellow eyes.

Hemodynamic alterations in CRA and OA may occur secondary to the vein occlusion as a result of increased intravascular pressure transferred through the capillary bed to the arterial side. ${ }^{11}$ Impaired arterial blood flow may partly be related to secondary changes in the retrobulbar arterial circulation, decreased PSV and high vascular resistance following CRVO.

As opposed, Ozbek et al found that there were no statistically significant difference with regard to the Vmax, Vmin, RI of the CRA and OA between the affected and the unaffected fellow eyes of the CRVO group. ${ }^{12}$

There are studies showing that blood flow velocities in the CRA and OA did not differ significantly between the affected and contralateral eyes in patients with BRVO. ${ }^{13,14}$ In agreement with these studies, in BRVO group, blood flow characteristics in the CRA and OA of the affected eyes did not differ significantly from their healthy fellow eyes in this study.

Since the introduction of anti-VEGF agents, vision improvement and macular edema reduction in both CRVO and BRVO could be demonstrated for ranibizumab, aflibercept and dexamethasone. ${ }^{15,16}$

Aflibercept, also known as VEGF-trap, is a decoy receptor where two binding domains, the domain 2 of VEGFR1 and the domain 3 of VEGFR2, are connected to the fragment crystallizable region of human immunoglobulin. The kinetics of aflibercept/VEGFA binding have been found to be characterized by fast high association rate $\left(\mathrm{K}_{\mathrm{on}}\right)$, which is consistent with high stabilizing electrostatic energy. ${ }^{17}$

There are a lot of studies reporting that VEGF is a potent vasodilator in many vascular beds including the retina. ${ }^{14,18}$ The VEGF secretion secondary to hypoxia present in CRVO and BRVO diseases causes vasodilatation. Anti-VEGF agents cause vasoconstriction by inhibiting VEGF, which causes blood flow velocity changes.

Vasodilation and increased vascular permeability lead to leakage and edema within the retina. One possible ocular adverse effect of anti-VEGF agents may be the blockage of the action of VEGF on the retinal vessel diameter and blood flow. VEGF induces vessel dilation and increases ocular blood flow through a mechanism involving increased nitric oxide (NO) production. ${ }^{18,19}$

While VEGF directly stimulates endothelial cell proliferation and migration, VEGF may act as a negative regulator of pericyte function. ${ }^{20}$ The modulatory role of pericytes toward the endothelial proliferative stimulus involves the activation of 
Table 6 Changes in hemodynamic parameters in branch retinal vein occlusion group after injection

\begin{tabular}{|c|c|c|c|c|}
\hline BRVO & Before injection & Ist week & I st month & $P$-value \\
\hline \multicolumn{5}{|c|}{ Ophthalmic artery } \\
\hline PSV & $38.5 \pm 3.11$ & $35.31 \pm 2.14$ & $34.38 \pm 1.94$ & 0.627 \\
\hline EDV & $12.56 \pm 1.26$ & $12.94 \pm 0.92$ & $12.50 \pm 1.18$ & 0.938 \\
\hline Vort & $25.53 \pm 2.11$ & $24.13 \pm 1.40$ & $23.31 \pm 1.5 \mid$ & 0.405 \\
\hline RI & $2.30 \pm 0.16$ & $1.89 \pm 0.24$ & $1.97 \pm 0.18$ & 0.099 \\
\hline \multicolumn{5}{|c|}{ Central Retinal Artery } \\
\hline PSV & $18.63 \pm 2.94$ & $13.69 \pm 1.56$ & $|0.8| \pm 0.5 \mid$ & 0.024 \\
\hline EDV & $6.50 \pm 1.13$ & $5.19 \pm 0.84$ & $3.44 \pm 0.20$ & 0.020 \\
\hline Vort & $12.56 \pm 2.02$ & $9.44 \pm 1.17$ & $7.22 \pm 0.40$ & 0.066 \\
\hline RI & $2.02 \pm 0.19$ & $1.91 \pm 0.22$ & $2.22 \pm 0.14$ & 0.099 \\
\hline
\end{tabular}

cytosolic phospholipase A2 (CPLA-2)/Cyclooxygenase-2 (COX-2) pathway. In the context of proliferative retinopathies, COX-2 mainly generates prostaglandin E2 (PGE2). Activation of CPLA-2/COX-2 may induce VEGF expression. Giurdanella et al reported that therapeutic anti-VEGF agents have a direct impact on pericyte survival and/or on the production of potentially relevant autocrine and paracrine factors, such as VEGF and PGE2. ${ }^{21}$ In another study, Giurdanella et al showed that PGE2 release induced by exogenous VEGF was reduced by aflibercept. ${ }^{22}$

Anti-VEGF agent has been associated with ischemic retinal and choriocapillaris changes after its intraocular administration, suggesting circulatory disturbances as a consequence of the treatment. ${ }^{23-26}$

Bonnin et al showed that intravitreal bevacizumab significantly reduces circulatory blood flow velocities in the posterior ciliary artery, CRA and OA in patients with AMD and suggest that antiangiogenic therapy may impair the native choroidal and retinal vascular supply. ${ }^{27}$

Papadopoulou et al hypothesize that anti-VEGF agents decrease retinal arteriolar diameter directly by blocking the production of NO and may lead to retinal arteriolar vasoconstriction. $^{28}$

It is known that steroids cause vasoconstriction through the specific receptors located on the vascular endothelium and the vascular smooth muscle cells. ${ }^{29}$

In the literature, it has been shown that intravitreal steroids may cause changes in ocular blood flow. ${ }^{30,31}$ Some studies have shown that the distal arterial obstruction increases the PSV of the arteries that supplies the eye. Triamcinolone acetonide (TA) may affect the ocular blood flow by its vasoconstrictive effect on the peripheral arterial resistance. $^{32,33}$
Several studies have examined the effects of various treatments for retinal vein occlusion on retrobulbar blood flow parameters. ${ }^{30-39}$

Cekic et al observed increment in the PSV of the CRA at the end of the first week and at the end of the first month after intravitreal TA injection in the RVO patients. ${ }^{30}$

A study by Sacu et al demonstrated a significant vasoconstriction following intravitreal ranibizumab treatment in arteries but more pronounced in veins affected by BRVO after a follow-up of 3 months. ${ }^{39}$

As opposed, Anayol et al demonstrated that there was no effect of intravitreal TA injection on the ocular blood flow during the follow-up period in the CRVO eyes compared with the fellow eyes. ${ }^{37}$ In another study, Eibenberger et al researched the effect of dexamethasone implant on retrobulbar blood flow velocities in RVO and they found that there were no changes in the flow velocities. But the patients who had been treated with anti-VEGF previously were included in the study. ${ }^{40}$

In our study, there were 21 patients with CRVO. Aflibercept treatment was applied to 10 patients and dexamethasone treatment was applied to 11 patients. In the BRVO group, all patients were treated with aflibercept therapy.

In our study, correlating with the literature, in the CRVO group, we found a significant decrease in flow parameters in the OA and the CRA after both dexamethasone and antiVEGF injection groups. When we compare the changes in anti-VEGF and dexamethasone groups, we did not find any significant difference between injection type and results.

In the BRVO group, there was no change in the flow parameters for the OA, but Vmax and Vmin values for the CRA were significantly decreased compared to the preinjection with anti-VEGF. 
But we did not find any significant change in the value of RI both in CRVO and BRVO groups.

In our study, we did not encounter any side effects such as vitreous hemorrhage, retinal detachment, endophthalmitis after intravitreal injections. Reibaldi et al report that prophylactic antibiotic therapy is associated with a significantly increased risk of endophthalmitis after intravitreal injection of anti-VEGF agents. ${ }^{41}$ Povidone-iodine antisepsis is the most important proven prophylaxis against endophthalmitis.

One of the limitations of our study is the fact that our sample size is small with absence of a control group. For comparison, we used the unaffected fellow eyes of the patients. However, there are studies reporting that in RVO there may be changes in the other eyes that are not affected.

Currently, intravitreal corticosteroid agents and intravitreal anti-VEGF agents are the common clinical therapies for macular edema secondary to CRVO. Nevertheless, these different drug treatment strategies have not been comprehensively compared; there are many studies in the literature evaluating the effects of anti-VEGF or steroid injections, but either anti-VEGF or steroid was evaluated in these studies. One of the features of our study is that the comparison of steroid and anti-VEGF injection groups was performed.

After treatment, there was a decrease in both OA and CRA values in CRVO eyes, but only a decrease in CRA values in BRVO group. We think the amount of VEGF as a possible cause that is higher in CRVO.

Vasoconstriction that is caused by the application of antiVEGF and dexamethasone may cause further ischemia and alert for early detection of ischemic changes. To avoid secondary effects, it is vital to be alert; it is important to follow up patients closely for early detection of ischemic changes.

\section{Disclosure}

The authors declare that they have no conflicts of interest or funding from any organizations to disclose.

\section{References}

1. Eye Disease case control study group. Risk factors for central retinal vein occlusion. Arch Ophthalmol. 1996;114:545-554.

2. Kaldırım HE, Yazgan S. A comparison of three different intravitreal treatment modalities of macular edema due to branch retinal vein occlusion. Int Ophthalmol. 2018;38(4):1549-1558. doi:10.1007/ s10792-017-0618-z

3. Li J, Paulus YM, Shuai Y, Fang W, Liu Q, Yuan S. New developments in the classification, pathogenesis, risk factors, natural history and treatment of branch retinal vein occlusion. J Ophthalmol. 2017;2017:4936924. doi:10.1155/2017/4936924. Epub 2017 Mar 12.

4. Sawada O, Ohji M. Retinal vein occlusion. Dev Ophthalmol. 2016;55:147-153. doi:10.1159/000438971
5. Ehlers JP, Kim SJ, Yeh S, et al. Therapies for macular edema associated with branch retinal vein occlusion. Ophthalmology. 2017;124(9):1412-1423. doi:10.1016/j.ophtha.2017.03.060

6. Dimitrova G, Kato S. Color doppler imaging of retinal dieases. Survey of Ophthalmol. 2010;55(3):193-214. doi:10.1016/j. survophthal.2009.06.010

7. Keyser BJ, Flaharty PM, Sergott RC, Brown GC, Lieb WE, Annesley WH. Color Doppler imaging of arterial blood flow in central retinal vein occlusion. Ophthalmology. 1994;101:1357-1361.

8. Pichot O, Gonzalvez B, Franco A, Mouillon M. Colour Doppler ultrasonography in the study of orbital and ocular vasclar diseases. J Fr Ophthalmol. 1996;19:19-31.

9. Tranquart F, Arsene S, Giraudeau B, et al. Initial color Doppler findings in retinal vein occlusion. J Clin Ultrasound. 2000;28(1):28-33.

10. Williamson TH, Baxter GM. Central retinal vein occlusion, an investigation by color Doppler imaging. Blood velocity characteristics and prediction of iris neovascularization. Ophthalmology. 1994;101 (8):1362-1372.

11. Fujino T, Curtin VT, Norton EWD. Experimental central retinal vein occlusion. A comparison of intraocular and extraocular occlusion. Arch Ophthalmol. 1969;81:395-406.

12. Ozbek Z, Saatci AO, Durak I, Kaynak S, Ergin MH, Oner B. Colour Doppler assessment of blood flow in eyes with central retinal vein occlusion. Ophthalmologica. 2002;216:231-234. doi:10.1159/ 000063851

13. Arsene S, Giraudeau B, Le Lez ML, Pisella PJ, Pourcelot L, Tranquart F. Follow up by color Doppler imaging of 102 patients with retinal vein occlusion over 1 year. Br J Ophthalmol. 2002;86 (11):1243-1247. doi:10.1136/bjo.86.11.1243

14. Ferrara N, Gerber HP. The role of vascular endothelial growth factor in angiogenesis. Acta Haematol. 2001;106:148-156. doi:10.1159/ 000046610

15. Pacella E, Pacella F, La torre G, et al. Testing the effectiveness of intravitreal ranibizumab during 12 months of follow-up in venous occlusion treatment. Clin Ter. 2012;163(6):413-422.

16. Bucolo C, Gozzo L, Longo L, Mansueto S, Vitale DC, Drago F. Long-term efficacy and safety profile of multiple injections of intravitreal dexamethasone implant to manage diabetic macular edema: a systematic review of real-world studies. J Pharmacol Sci. 2018;138 (4):219-232. doi:10.1016/j.jphs.2018.11.001

17. Platania CB, Paola LD, Leggio GM, et al. Molecular features of interaction between VEGFA and anti-angiogenic drugs used in retinal diseases: a computational approach. Front Pharmacol. 2015;29 (6): 248 .

18. Tilton RG, Chang KC, Lejeune WS, Stephan CC, Brock TA, Williamson JR. Role for nitric oxide in the hyperpermeability and hemodynamic changes induced by intravenous VEGF. Invest Ophthalmol Vis Sci. 1999;40:689-696.

19. Ku DD, Zaleski JK, Liu S, Brock TA. Vascular endothelial growth factor induces EDRF-dependent elaxation in coronary arteries. $\mathrm{Am} \mathrm{J}$ Physiol. 1993;265:586-592.

20. Greenberg JI, Shields DJ, Barillas SG, et al. A role for VEGF as a negative regulator of pericyte function and vessel maturation. Nature. 2008;456:809-813. doi:10.1038/nature07424

21. Giurdanella G, Anfuso CD, Olivieri M, et al. Aflibercept, bevacizumab and ranibizumab prevent glucose-induced damage in human retinal pericytes in vitro, through a PLA2/COX-2/VEGF-A pathway. Biochem Pharmacol. 2015;96(3):278-287. doi:10.1016/j.bcp.2015.05.017

22. Giurdanella G, Lazzara F, Caporarello N, et al. Sulodexide prevents activation of the PLA2/COX-2/VEGF inflammatory pathway in human retinal endothelial cells by blocking the effect of AGE/ RAGE. Biochem Pharmacol. 2017;142:145-154. doi:10.1016/j. bcp. 2017.06 .130

23. Ameri H, Chader GJ, Kim JG, Sadda SR, Rao NA, Humayun MS. The effects of intravitreous bevacizumab on retinal neovascular membrane and normal capillaries in rabbits. Invest Ophthalmol Vis Sci. 2007;48:5708-5715. doi:10.1167/iovs.07-0731 
24. Peters S, Heiduschka P, Julien S, Ziemssen F, Fietz H, Bartz-Schmidt KU. Tübingen Bevacizumab Study Group, Schraermeyer U. Ultrastructural findings in the primate eye after intravitreal injection of bevacizumab. Am J Ophthalmol. 2007;143:995-1002. doi:10.1016/j.ajo.2007.03.007

25. Kim KS, Chang HR, Song S. Ischaemic change after intravitreal bevacizumab (Avastin) injection for acular oedema secondary to nonischaemic central retinal vein occlusion [letter]. Acta Ophthalmol. 2008;86:925-927. doi:10.1111/j.1755-3768.2008.01175.x

26. Lee CS, Koh HJ. Multiple retinal haemorrhages in diabetic retinopathy after adjunctive intravitreal bevacizumab (Avastin) with pars plana vitrectomy [letter]. Acta Ophthalmol. 2008;86:812-813. doi:10.1111/j.1600-0420.2007.01111.x

27. Bonnin P, Pournaras JA, Lazrak Z, et al. Ultrasound assessment of shortterm ocular vascular effects of intravitreal injection of bevacizumab (Avastin) in neovascular age related macular degeneration. Acta Ophthalmol. 2010;88:641-645. doi:10.1111/j.1755-3768.2009.01526.x

28. Papadopoulou DN, Mendrinos E, Mangioris G, Donati G, Pournaras CJ. Intravitreal ranibizumab may induce retinal arteriolar vasoconstriction in patients with neovascular age-related macular degeneration. Ophthalmology. 2009;116:1755-1761. doi:10.1016/j.ophtha.2009.03.017

29. Bakbak B, Ozturk BT, Gedik S, Koktekir BE, Gonul S. Can intramuscular corticosteroid injection cause nonarteritic anterior ischemic optic neuropathy? Clin Ophthalmol. 2013;7:633-635. doi:10.2147/ OPTH.S43862

30. Cekic O, Bardak Y, Tig SU, et al. Hemodynamic response to intravitreal triamcinolone in eyes with macular edema: intravitreal triamcinolone and ocular blood flow. Int Ophthalmol. 2007;27(5):313-319. doi:10.1007/s10792-007-9080-7

31. Cekic O, Bardak Y, Yesildag A. Color Doppler imaging of ocular blood flow after combined photodynamic theraphy with intravitreal triamcinolone in age-related macular degeneration. Curr Eye Res. 2011;36(2):149-153. doi:10.3109/02713683.2010.533809

32. Granata A, Fiorini F, Andrulli S, et al. Doppler ultrasound and renal artery stenosis: an overview. J Ultrasound. 2009;12(4):133-143. doi:10.1016/j.jus.2009.09.006
33. Li JC, Jiang YX, Zhang SY, Wang L, Ouyang YS, Qi ZH. Evaluation of renal artery stenosis with hemodynamic parameters of Doppler sonography. J Vasc Surg. 2008;48(2):323-328. doi:10.1016/j.jvs.2008.03.048

34. Avunduk AM, Dinç H, Kapıcıoglu Z, Ugurlu S, Dayanır V, Korkmaz E. Arterial blood flow characteristics in central retinal vein occlusion and effects of panretinal photocoagulation treatment: an investigation by color Doppler imaging. Br J Ophthalmol. 1999;83(1):50-53. doi:10.1136/bjo.83.1.50

35. Tranquart F, Arsene S, Aubert-Urena AS, et al. Doppler assessment of hemodynamic changes after hemodilution in retinal vein occlusion. J Clin Ultrasound. 1998;26(3):119-124.

36. Williamson TH. A "'throttle" mechanism in the central retinal vein in the region of the lamina cribrosa. Br J Ophthalmol. 2007;91(9):11901193. doi:10.1136/bjo.2006.102798

37. Anayol MA, Toklu Y, Kamberoglu EA, et al. Short-term effects of intravitreal triamcinolone acetonide injection on ocular blood flow evaluated with color doppler ultrasonography. Int J Ophthalmol. 2014;7:811-815. doi:10.3980/j.issn.2222-3959.2014.05.13

38. Nagaoka T, Sogawa K, Yoshida A. Changes in retinal blood flow in patients with macular edema secondary to branch retinal vein occlusion before and after intravitreal injection of bevacizumab. Retina. 2014;34:2037-2043. doi:10.1097/IAE.0000000000000172

39. Sacu S, Pemp B, Weigert G, et al. Response of retinal vessels and retrobulbar hemodynamics to intravitreal anti-VEGF treatment in eyes with branch retinal vein occlusion. Invest Ophthalmol Vis Sci. 2011;52:3046-3050. doi:10.1167/iovs.10-5842

40. Eibenberger K, Schmetterer L, Dreindl S, et al. Effects of intravitreal dexamethasone implants on retinal oxygen saturation, vessel diameter and retrobulbar blood flow velocity in ME secondary to RVO. Invest Ophthalmol Vis Sci. 2017;58:5022-5029. doi:10.1167/iovs.17-22229

41. Reibaldi M, Pulvirenti A, Avitabile T, et al. Pooled estimates of incidence of endophthalmitis after intravitreal injection of antivascular endothelial growth factor agents with and without topical antibiotic prophylaxis. Retina. 2018;38:1-11. doi:10.1097/ IAE.0000000000001583
Therapeutics and Clinical Risk Management

\section{Publish your work in this journal}

Therapeutics and Clinical Risk Management is an international, peerreviewed journal of clinical therapeutics and risk management, focusing on concise rapid reporting of clinical studies in all therapeutic areas, outcomes, safety, and programs for the effective, safe, and sustained use of medicines. This journal is indexed on PubMed Central, CAS,

\section{Dovepress}

EMBase, Scopus and the Elsevier Bibliographic databases. The manuscript management system is completely online and includes a very quick and fair peer-review system, which is all easy to use. Visit http://www.dovepress.com/testimonials.php to read real quotes from published authors. 